\title{
MORFOLOGIA GENITAL DE CAMARÕES PENEÓIDEOS
}

\author{
Denadai, A.C. ${ }^{1,}$; Garcia, J.R. ${ }^{1}$; Zara, F. J. ${ }^{2}$ \& Castilho A.L. ${ }^{1}$ \\ ${ }^{1}$ Universidade Estadual Paulista Júlio de Mesquita Filho (UNESP), Campus Botucatu, \\ Instituto de Biociências - Zoologia - NEBECC. \\ ${ }^{2}$ Universidade Estadual Paulista Júlio de Mesquita Filho (UNESP), Campus Jabuticabal, Faculdade de Ciências \\ Agrárias e Veterinárias - Biologia Aplicada à Agropecuária. \\ *Autor correspondente: acdenadai@outlook.com
}

O objetivo deste estudo foi descrever o télico e o petasma de cinco espécies de camarões peneóideos e determinar o grau de complexidade do petasma ao longo da tendência evolutiva. As cinco espécies consideradas (Litopenaeus schmitti (Burkenroad, 1936), Pleoticus muelleri (Spence Bate, 1888), Rimapenaeus constrictus (Stimpson, 1871), Farfantepenaeus brasiliensis (Latreille, 1817) e Sicyonia typica (Boeck, 1864)) foram coletadas na costa dos estados de São Paulo e Santa Catarina durante 2006 e entre 2011 e 2016 utilizando-se de um barco camaroeiro. Os indivíduos foram identificados e classificados de acordo com o sexo, sendo o petasma (machos) e o télico (fêmeas) destacados e fixados em solução Karnovsky (2,5\% - glutaraldeído; 2\% - paraformaldeído) durante 24-48 horas. Posteriormente, as genitálias foram desidratadas durante 20 minutos em concentrações crescentes de etanol e foram conduzidas aos procedimentos de análise ultraestrutural em Microscopia Eletrônica de Varredura (MEV). Todas as espécies apresentaram petasma simétrico com a presença de cincinulli e costa ventral evidente (exceto $S$. typica). Litopenaeus schmitti foi caracterizado pela presença de muitos espinhos no lobo dorsolateral do petasma, enquanto em $R$. constrictus foi possível observar a presença de canais e projeções do tipo espinho. Em S. typica, foi possível identificar, além dos canais, estruturas em forma de bico. Já o télico das espécies foi composto por placas, proeminências, protuberâncias medianas e/ou simples continuidade das placas. Mediante as observações, propõe-se a divisão da genitália masculina em três classes (1: petasma aberto; 2: petasma semiaberto ou semitubular e 3: petasma fechado) e divide-se a genitália feminina em duas partes (1: Lâmina e 2: Proeminências, protuberâncias ou continuidade da lâmina). Não foi possível evidenciar um aumento em complexidade do petasma nas espécies estudadas, mas foi possível identificar a presença de canais e estruturas do tipo espinho/ bico como caracteres derivados dentre os camarões peneóideos.

Palavras-chave: evolução genital, morfologia, petasma, télico, ultraestrutura.

Financiamento: FAPESP № 2010/50188-8, 2016/20177-0; CAPES/Ciências do Mar № 23038.004310/2014-85. 